ti u to those farticulas. When it was desirable to limit the application of lithotrity to calculi of, say, one inch and a half diameter, it was important to ascertain, by some easily managed method of measuring, what were their dimensions in every case. But now that the scope of lithotrity is considerably increased, all that is requisite to be learned is, whether the stone is an exceptionally large and hard one, and whether any unnatural narrowing of the canal is present; and both these points are almost sufficiently determined by an ordinary sounding in practised hands. At all events it is unnecessary to make any further examination for the purpose of diagnosis until the patient has been placed under the influence of an anæesthetic upon the operating table, the surgeon having full liberty to exercise his judgment and act as circumstances demand.

Invariably, as soon as the patient is thus prepared for operation, I pass a full-sized conical steel-plated sound-say about No. 15 (Euglish), in order to determine that most important point of urethral calibre before touching the stone. If the urethra is healthy, and of course in the very great majority of cases it is so, the instrument has passed with perfect ease, and may probably be followed by No. 16 or 17 in an elderly adult, by which term I mean a man of sixty years and upwards. I am sure the urethra is more capacious in such patients than in those whose age is between thirty and fifty years. In these latter the urethra often resents any active distension, and the bladder also more readily becomes inflamed than in older patients. With a urethra admitting the easy passiog of No. 16 almost anything is possible, and suffices for almost any calculus; but if $I$ am dealing with one which weighs, in my judgment, about two ounces and more, I am glad to use larger sizes, and No. $18 \mathrm{I}$ have never found it necessary to exceed. But if the stone is known to be small, No. 14 amply suffices, and there can be no reason for going beyond it. This is the size which was mostly used with the original instrument of Clover in 1866, and for all ordinary purposes answers admirably.

The lithotrite is next introduced. With small and medium-sized stones, a light instrument of the half-fenestrated pattern-that is, the lower portion of the male blade penetrating the fimale blade, which prevents the possibility of blocking by débris, while the upper portion is flat and crushes the stone into small fragments-is, I think, the best. This mode of construction is applicable for a wide range of size in calculus, answering for any one of uric acid beluw about an inch and $a$ half in length. To accomplish the first fracture of such a one, or to crush into fragments a larger calculus, a fully fenestrated lithotrite is better. There are some oll forms of blade which have been in use for fifty years, which cannot, I think, be excelled; so numerous are the patterns which have been employed, that it is difficult now to imagine a new design.

To proceed, supposing that a considerable quantity of débris has been mane, the calculus being large, it is advisable to withdraw the lithotrite, to introduce an evacuating-sound and attach the aspirator, so as to withdraw the débris already made before crushing more. When this is removed, the same or a lighter insirument may crush the fragments into débris, before again using the evacuator. By this time, probably, the remaining portion is not considerable, and another introduction of the lithotrite, followed by another aspiration, very likely empties the bladder. If, however, a fragment or two are heard and felt to strike the end of the evacuator, yet do not pass through it, they are probably just too large to issue, and require another crushing before the task is completed. There is certainly now no difficulty in removing any last fragment from the bladder, the more powerful aspirators emptying the cavity so efficiently that no other instrument is necessary for the purpose; while by no sound is the last fragment found so well as by the evacuating catbeter, against which contact of the fragment is certain to be felt or heard, through the action of the outrushing current of water.

In regard to aspirators, the original instrument of Clover, simple in the extreme, is a very good instrument, and requires only some modification to be as efficient as most of the modern ones. For my own aspirator $I$ have provided a tap with funnel-shaped opening to the upper part of the indiarubber ball, by which to fill it, and to remove air accidentally introduced, wbich offers a decided advantage. Last year $I$ attached to the end of the evacuator in the interior of the glass receiver a light wire valve, which while it admits any fragments to enter, renders their escape impossible; its action meantime being always visible to the operator.
After the operation the patient remains in bed, and rarely requires any special management, except sometimes that which a simple traumatic cystitis demands-namely, absoluto rest in bed; occasionally the urine neutralised by potash hot hip baths; mild diet; and watchful care that chronic retention of urine does not occur, or is not permitted to continue unrelieved; avoiding on the other hand undue or unnecessary interference by means of catheters. But of all the agents for rapidly removing suhacute or chronic cystitis after lithotrity, nothing equals mild injections of nitrate of silver, the effect of which is sometimes almost instantaneous, I use only half a grain of the salt in four ounces of warm water at first, gradually increasing to a solution three times that strengtb, beyond which it is rarely necessary to go. Usually one application a day, sometimes two, will, in the course of three or four days, remove the painful symptom. and produce clear and healthy urine.

My own experience of the system of treating all calculi but the very largest, by a single sitting of lithotrity, dates from shortly before Christmas, 1878; the first example being a case which I saw with Sir Spencer Wells, who was present at the operation. Since that time I have adopted the system of completing the operation at a single sitting for every case in which lithotrity appeared to be possible, with two exceptions only, to be described immediately. The total number of adult male patien rs on whom I have operated during the period referred to, a term of ratber more than five years, is 211 . Of these, tifteen have been by lithotomy, and of course forming the largest and worst cases, with seven deaths. There remain, therefore, 196 cases treated by lithotrity. One of these was a Portuguese gentleman, No. 535, in my collection before you, to whom $\mathrm{Mr}$. Clover thought it prudent to administer chloroform only for a very limited time. $\mathrm{He}$ had five sittings to remove a stone weighing no less than 787 grains, and made a good recovery. The other exception was that of a large oxalate of lime calculus, No. 538, which at that time I preferred to crush in four sittings. The débris weighs 640 grains; he js now perfectly well. Every one of the remaining cases, 194 in number, has been treated at a single sitting, making a total of 196 cases of lithotrity at a single sitting, with 10 deaths, or just 5 per cent. Total of 211 cases of adults by the two operations, with 17 deaths, or 8 per cent. The mean age of these patients was over sixty years. And this is a result which hitherto has, I need bardly say, not been approached by any other mode of treating cal culus in the adult. This subject, however, will be illustrated more fully in the succeeding lecture, when I shall present the results of my entire series, embracing upwards of 800 cases by the two operations.

I have crushed several stones of uric acid, and one of oxalate of lime, considerably upwards of an ounce in weight The largest uric acid calculus $I$ removed at a single sitting weighed two ounces and three-quarters, and occupied me seventy minutes. The patient was seventy years of age, and made a capital recovery. I cannot speak too highly of the results thus attained. Indeed, nothing need be added to the figures I bave adduced above, which exceeded any expectation I could have previously formed as to the success of operating on men upwards of sixty years of age, with stones of all sizes. In conclusion, I think we must admit that the operation of lithotrity at a single sitting bids fair to supersede lithotomy for the adult calculous patient in all cases except those in which the stone is of rare and exceptional size.

\section{ON CHARCOT'S JOINT DISEASE}

BY W. HALE WHITE, M.D., M.R.C.P., SENIOR DEMONSTRATOR OF ANATOMY AT GUY'S HOSPITAL.

DURING the last few months the subject of Charcot's joint disease in sssociation with locomotor ataxy has come before the Pathological and Clinical Societies three times, and on each occasion observers of great note have been found to state their scepticism as to the existence of any definite anthropathy such as Charcot describes. Thus, when Mr. Arbuthnot Lane brought his paper on Mollities Ossium, Rheumatoid Arthritis, and Charcot's Disease before the Pathological Society, ${ }^{1}$ both Mr. Hulke and Dr. Goodhart seemed to consider that all the cases which had from time to 
time been shown them as examples of Charcot's disease were really rheumatoid arthritis; and when Mr. Clement Lucas read his paper before the Clinical Society, ${ }^{2}$ Dr. Moxon stated his belief that Charcot's joint disease was only rheumatic arthritis occurring in patients affected with locomotor ataxy. If no others than the three gentlemen just mentioned were doubtful of the entity of the disease, the fact of their hesitation to accept it would make it worth while to inquire into the exact position of the question as to whether or not it is a distinct malady. It seems to me that three views may be held with regard to it. . In the first place, there is that of Charcot and his followers, who state that the joint disease is a distinct specific arthropathy peculiar to locomotor ataxy. Secondly, there is the view that it is an ordinary arthritis, somewhat modified by the conditions of the patient, but dependent upon nerve lesion, as are the arthropathies found after injuries to nerves. Thirdly, there is the view that it is merely a rheumatic or some other form of arthritis which has occurred in an ataxic patient, the coincidence of their occurrence being pure chance.

To take Charcot's view first. We are here dependent entirely upon the clinical and post-mortem characteristics, because up to the present time no one has been able to state in what part of the nervous system the joint centre, if there be such a spot, exists. Charcot was at first inclined to place it in the anterior cornua, but this theory has been abandoned because post-mortem experience has shown that the disease may be present without any change in the anterior cornua being demonstrable. Then the hypothesis has been put forward by Buzzard that there is in the medulla an arthritic centre which becomes affected in locomotor ataxy. He urges in favour of this view the frequent association of gastric crises with joint trouble; but although this is an ingenious hypothesis, it is as yet hardly certain enough to allow us to argue that because there is a joint centre in the medulla, therefore we may look for joint lesions of a specific nature in locomotor ataxy. It has also been urged that the lesions of the peripheral nerves discovered by Pitres andVaillard are the cause of the artbritis ; but against this is the fact that in some cases in which the joint trouble has been present there has been no peripheral nerve change. Thus we see, as we are unable to argue a priori from the fact of a nervous cause for the joint troubles in locomotor ataxy being constantly present that therefore they are probably peculiar to that malady, the view we are now considering depends entirely uron the clinical and post-mortem characteristics of the disease. The clinical symptoms are, according to Charcot, ${ }^{3}$ briefly these:-Without appreciable external cause in the slightly advanced period of the locomotor ataxy this arthropathy is developed; the first phenomenon discernible is extreme tumefaction, which is formed by a considerable hydarthrosis, and an engorgement presenting a hard consistence; usually there is no fever, pain, or cracking sound. At the end of some months the swelling disappears and all returns to the normal state, or in other cases serious disorder, such as crackings, dislocations, \&c., remain in the joints; the order of frequency is knee, shoulder, elbow, hip, wrist. At the meetings of the Pathological and Clinical Societies just referred to neither Mr. Hulke, Dr. Moxon, nor Dr. Goodhart-all distinguished clinicists with a large field of observationknew anything of this train of symptoms. In thirty cases of locomotor ataxy which be had most carefully observed, Dr. Moxon had not detected any specific arthritic changes. Charcot, however, found five patients presenting such changes among fifty examined. The following quotation from Senator ${ }^{4}$ will, I think, show that he is not certain that the arthropathy of locomotor ataxy is a distinct disease :"Charcot and his pupils subsequently drew attention to the occurrence of peculiar articular swellings in locomotor ataxy and other forms of paralysis

It is quite true these articular swellings did not invariably present the characters of arthritis deformans; they often set in with abundant effusion into the joint, a symptom quite foreign to the latter disease ; in other cases, however, the characteristic morbid changes developed themselves either at once or after a time." Further on he says: "To distinguish arthritis deformans at this early stage from the articular neuroses there are hardly any criteria." Ball ${ }^{5}$ is very emphatic in pointing

2 Ibid., March 1st, 1884, p. 414

3 Disease of the Nervous System, S'econd Sories, Sydenham Society's Transactions, p. 54

'Ziemssen's Cyclopredia, Engliah Trans., vol. xvi., pp. 152 and 160

5 Gazutte des Hopitaux, 1860, p. 234 . out the distinctions between the two maladies, but the impression one gets from reading his article is that there are many similarities. Thus he records two cases in which are presented heat and redness of the joint, and other connecting links might be found in his descriptions.

We have heard a good deal about the frequency with which these cases have been overlooked by surgeons, and there is the story told of a patient who, although suffering from Charcot's joint disease, was shown to the candidates at one of the examining boards as a case of rheumatoid arthritis but surely all this tells strongly in favour of the view that there are no distinct clinical characteristics of Charcot's disease, for those surgeons who are accused of having made such error, seeing, as they do, a large number of cases of rheumatoid arthritis, would have been the first to set aside these cases as peculiar had they really been so. The case that was used for examination purposes cannot have been so very out of the common if it passed through several surgeons' hands as a case sufficiently typical to show to candidates.

Turning again to Charcot's own account of the disease, we find that he admits " the analogy existing as regards cracking sounds, the osseous tumefactions, \&c." It is perhaps difficult to determine exactly how much is included under that "\&c." for a reference to his list of points of distinction between the two diseases will show that there is hardly a single symptom which is not in some measure common to his disease and an ordinary arthritis; thus pain, thickening of the synovial membrane, and hydarthrosis may be present in both. I have seen lately six cases of joint disease in locomotor ataxy, all of which were considered to be examples of Charcot's disease by some of those who had seen them, although not one of them was universally allowed to be an example of that malady; but I have never seen a case of joint disease in association with locomotor ataxy which was universally allowed not to be Charcot's disease. This is, of course, not logically conclusive, but still it is some evidence that whenever a patient is discovored with locomotor ataxy and a joint lesion somebody will be found who thinks it is a peculiar arthropathy. Although one or even two of the six cases above-mentioned were not typical instances of ordinary arthritis, there was not a single one that I should like to say could not be regarded as some form of that disease.

When we come to consider the pathological aspect of the joint lesion, it is evident at once that the peculiarities of Charcot's disease are not very striking; in fact, he himself says, "On the whole, anatomically speaking, our arthropathy is included in the group of dry arthritis," and certainly this is true of the specimen he presented to St. Thomas's Hospital Museum. I do not think that anybody on being shown that would say, without knowing the history of the case, that there was anything about the bone to distinguish it from a specimen of rheumatoid arthritis. The piece of the top of the humerus he presented to the Museum of the College of Surgeons (No. 1921), shows that the head of the bone has entirely disappeared. A smooth and partly eburnated surface is left, surrounded by bony outgrowtbs. It will be noted that these last two points are most characteristic of rheumatoid arthritis. This specimen is in a case with many other dried ones of joint mischief, and thus there is an excellent opportunity of noting the points in which it resembles them. The only other example I am acquainted with is the pelvis, which I exhibited to the Pathological Society, and which Prof. Charcot was kind enough to examine for me. He pronounced it to be a rare furm of the artbropathy he associates with locomotor ataxy. Now, this specimen undoubtedly presents a very unusual condition of things; the slight formation of new bone, the rarefaction of the normal bone, and the great deepening of the acetabula as a result of this, and the pressure in wards of the heads of the femora, go to build up a pelvis quite unlike anything which any Englishman to whom I have shown the specimen has seen. It was taken from a dissecting-room female subject; there is therefore a strong probability that it came from some infirmary bedridden subject. One thing is quite certain - namely, that she was in some public institution with a resident medical officer. Now, surely, considering how everyone is on the alert to find a case of Charcot's joint disease, had this patient presented symproms of locomotor ataxy, she would have been recorded in one of the journals, or we should have heard of it in some way or anotber. It should also be noticed that there was some slight evidence of formation of new bone, although the chief characteristics were undoubtedly the absence of stalactites and the predominance of the wearing away process; but 
considering that we have no evidence of locomotor ataxy, that both hips (which in Charcot's disease are but rarely affected) were here diseased, that there is some evidence of new bone formation, that the bones in old people are very liable to become light and thin, and, lastly, that in old people morbus coxæ senilis, which assumes divers forms, is common, is it not perhaps better to postpone definitely calling this specimen one of locomotor arthropathy, as our knowledge of this disease is still in its infancy

Specimens 1922 and 1922A in the Royal College of Surgeons Museum show how extremely diffieult it is to be sure of any distinct characters in the joints said to be affected with Charcot's disease. No. 1922 consists of the bones of the right upper extremity; they are all very wasted and much thinned, the shoulder-joint is destroyed, the head of the humerus gone, and the wrist bones are much atrophied, but the bones are no smaller than I have seen in an upper extremity which has been spastically contracted and disused for some years. The left knee-joint shows no production of stalactites, but the bones are so thinned that the first thing that suggested itself was that, whatever disease the patient suffered trom, she must have been unable to use her leg for some time. In the catalogue is the following: "Joint changes symmetrical; those most like locomotor ataxy occur in the shoulders." The writer then goes on to say that the joint changes present " just the features of Charcot's joint disease. It may be that the woman is ataxic, and in a poor bedridden cripple it is not easy to decide this point; if, however, it be thought probable that ataxia is present, the case still remains chiefly one of general rheumatism, for the joints are or have been almost all affected, and with remarkable symmetry, whilst none are positively dislocated." Surely if a case presents just the features of Charcot's joint disease but still remains chiefly one of general rheumatism, there cannot be much distinction between the two diseases.

One need not proceed in showing that it is doubtful whether this disease is a pathological entity, because Charcot himself allows that it is not, the only points he urges are that in it the productions of new bone are slight, whilst the wearing away is excessive. I have tried to show that these two points in the three specimens $I$ have seen are not so characteristic as to be very distinctive, and I hope to show that they may be accounted for in a simple way. I would refer the reader who is interested in the subject to the descriptions ${ }^{6}$ by Féré, and Charcot and Féré, of the specimens in Paris. Here the majority of the cases undoubtedly show the two points just mentioned; nevertheless, there are some which are not much worn away and some with new stalactites. Mr. Arbuthnot Lane has already shown in the paper referred to that in a patient with most of the joints affected with rheumatoid arthritis the jaw may present such characters as to make it indistinguishable from Charcot's arthropathy. This speaks for itself.

Let us consider next the hypothesis that this arthritis occurring with locomotor ataxy is really the same as is produced in joints after injuries to nerves. Weir Mitchell 7 says it is quite evident that injuries of the spine, diseases of the spinal cord and of the brain, and wounds or any form of lesions of nerves, are capable of developing in the joints inflammatory conditions, usually subacute, and which precisely resemble rheumatic arthritis in their symptoms and results, so that no clinical skill can discriminate between the two. The same author again ${ }^{8}$ says that the arthropathies due to nervous disease are so difficult to tell from rheumatism that they lend support to the theory that it is primarily a nervous disease. J. K. Mitchell, nearly fifty years ago, in the American Journal of Medical Science, also pointed out that obvious spinal cause may produce rheumatism characterised by heat, pain, redness, and tumefaction. It has also been shown by Gull that diseases of the cord will produce joint mischief. Ziemssen allows that injuries of the nervous system may be the cause of joint lesions. Charcot ${ }^{9}$ himself gives several cases, such as one of a tumour of the right hemisphere, in which the joints of the opposite side were affected ; he also shows that this cannot be due to a descending lesion, because it comes on too early, and for the same reason it cannot be due to functional inertia. Thus it appears there is no doubt that nerve lesions will produce joint disease indistinguishable from other well-known forms

6 Archives de Neurologie, Nos. 10, 11, and 18. Injuries to Nerves, p. 170

8 Spinal Arthropathies, Amer. Journal Med. Sciences, 1875, p. 339. 9 Arch. de Physiologio, 1868, p. 172 of arthritis. All authors who have written upon these arthropathies are of opinion that they are produced by inhibition of the trophic influence of certain nerves. There are perhaps some who still do not recognise the existence of trophic nerves, but at present the evidence is in support of their existence. Foster, who is always very cautious, considers that facts turn the balance in favour of trophic nerves. We must therefore allow the possibility of joint changes due to nervous lesion in a malady presenting such widespread alterations in the nervous system as does locomotor ataxy, but it is difficult to see the advantage of surrounding them with a halo of mystery; they may not be perhaps so acute as some nervous arthropathies, but still if they are due to a nervous change they must belong to that class, and $t$ can only result in confusion to separate them from it. They must also be inflammatory; it is always allowed that the destruction of trophic influence results in inflammation of a part; true it is that it may be modified by various circum. stances. Thus in the case of a joint inflammation not much new bone may be thrown out, but still it will belong to the same group. There can, it seems to me, be little doubt that not nearly all the cases that are described as Charcot's disease are really examples of an affection of the joints due to the destruction of some nervous influence; nevertheless, as I have just stated, we must allow that such is possible, although the admission lands us in considerable difficulties. Thus, if we allow that there is a trophic centre somewhere in the central nervous system which presides over the joints, some affection ought to supervene in them whenever the path from the centre to them is interrupted; for example, if the centre be in the medulla, as Buzzard supposes, whenever the nervous tract going from the medulla to the knee is injured we ought to get changes in the knee-joint, but we do not. The subjects of fractured spines may live for months without joint changes; severance of the cords in animals leads to no such result. Undoubtedly sometimes destruction of the cord will lead to joint mischief; but if the theory be true, it ought always to do so; just as section of the vagus al ways makes the heart go faster. The only way out of the difficulty is to imagine that the trophic influences descend in the sympathetic cord; this may be so, but at present we have no evidence of it.

The last of the three possible views is that the cases unde consideration are ordinary rheumatic or other forms of arthritis occurring in ataxic patients, indenendently of their nervous disease, although sometimes modified by the conditions enforced by it. This view will, I imagine, be found to satisfactorily explain a very large number of cases called Charcot's joint disease, whilst for the remainder we may invoke the aid of the theory which refers them to some tropic nerve lesion. We are in fact driven to it by exclusion, and it is supported by the numerous resemblances to chronic rheumatic arthritis which have already been shown to exist in many cases of so-called Charcot's joint disease. When it comes on late in the ataxic it may be, as Volkmann has suggested, a traumatic arthritis, for this condition must be prone to occur in patients always flinging their legs about, and, once set up, it is very unlikely to have much chance of getting well. In the bedridden cases there are all the conditions requisite for the production of this arthropathy. It is well known that joints but little subject to use are very liable to disease. Thus I know of a gentleman who was confined to his bed for some weeks on account of a severe strain of the hip. He first got up for a short time one evening, and on waking the next morning his knee-joint presented exactly the characters ascribed to Charcot's locomotor arthropathy, but this change was obviously merely due to the slight use to which he had put a joint which had been for a long time disused. Then, again, with regard to the thinning of bones and fractures. One has only to spend a week in a large dissecting-room to see that old bedridden people are peculiarly liable to have their bones very thin, and hence also very liable to fracture of them. The supporters of the view of the specific entity of the locomotor arthropathy admit that it is very rare; thus, Charcot himself puts it at one in every ten cases of ataxy, and this is a high proportion. We have just shown that the examples which occur late in the malady may be easily explained, without necessarily supposing them to be peculiar to ataxy; so that we have only those few left which come on in the early period of the disease, and when we remember that in these cases sometimes the joint may be red, sometimes there may be fever, sometimes there may be much pain, and sometimes effusion into the joint, it does seem, considering 
the avowedly few number of cases and the numerous $c$. nnecting links, somewhat rash to maintain that these are examples of an arthritis peculiar to locomotor ataxy. 'Tnen, again, in order to prove the case for a peculiar arthropathy, it must be shown that ataxics are more liab'e to joiut trouble than other people, for unless they are less liable to rheumatic arthriris and common joint diseases than the rest of mankind, they will have these troubles together with their special ones, so that a larger percentege of ataxics than of ordinary people will have joint disetse. But this has never been shown to be so, and my impres. sion is that ataxics would not be found to bs more liable to joint disease than any other class of people. But we are told post mortem the difference is to be seen, inasmuch as the wearing away process predominates over the production of stalacutes. The conditions under which ataxics are placed will, it seems to me, account for this, which, as shown above, is not always very marked; their whole vital power is lowered by the restraint imposed upon them by their malady. Thus they are often confined to bed, and various depressing complications areliable to supervene. Is it, then, strange that the new bone should not be thrown out very abundantly? The excessive wearing away can easily he accounted for when we remember the extreme thinness of the bones. If we look to other diseases, we see how the general condition of the patient modifies their course; for example, if a patient be in a very low condition, the granulations on an ulcerating surface will be small and grow slowly, whilst if he be in robust bealth they will be abundant and grow quickly. If in this case, why in that of the joint mischief may not the condition of the patient be used to explain a seeming peruliarity ?

Further observation may show that C'arcol's disease ia a condition specially associated with Jocomotor ataxy. My object has merely been to point out that this has not been yet completely proved, and to present the arguments against it; also to suggest that whilst some cases of Charcot's disease may, like other nervous artbropthies, be due to the alteration of some trophic inlluence, a large number of cases that have been brought forward as a spectal disease are ordinary and well-known forms of arthritis, pussibly somewhat modified by the condition of the patient.

St. Thomas's-street, S E.

\section{CHARCOT'S JOI I T DISEASE} (ATAXIC ARTHROPATHY; TABETIC ARTHRITIS).

By PHILIP H. KIDD, M.B. EdIN,

ASSISTANT-SURGEON TO THE IIARTLEPONLS FHIENDLY SOCIETIES' MEdiCal assuchation.

THE comparative rarity of this disease, its recent discovery, and the obscurity that still hangs over many points alike in its pathology and its clinical picture, justify, I think, the somewhat detailed description I have given of the following case :-

$\mathrm{Mr}$. - - between forty-two and for $\mathrm{y}$-three years of age, a small shopkeeper, began about a year and a half ago to complain of pains in his thighs and the lower part of his abdomen, which be compares to being slıt with a knife, and for the relief of which he used to carl up his left leg, so that his heel touched the trunk on the same side, and take long walks. Shortly afterwards he noticed a crackling sound in his left thigh whenever he moved it, and this was succeeded by swelling over the region of the hip-joint, which seems to have reached as far as half-way down the thigh on the outside, and was accompanied by a more circumscribed swelling in front of the joint, thus showing, I take it, that it was a true effusion into the cavity of the articulation. He then called in the medical officers of the Association, who prescribed for him, and painted his hip with iodine. Treatment was followed by subsidence of the swelling, but the crackling sound remained, and the pains descended in to his leg, and about that time he also noticed wasting of the leg. He was able soon afterwards to get about by means of a stick, and attendance on him ceased for some monthe. On March 8th last, he first noticed the crackling in the right hip, unaccompanied this time by any swelling, and as this increased, and the corresponding leg and thigh began also to waste, he asked for further attendance.

On April 4th I saw the patient, and elicited the following facts. He has always lived a steady, quiet life, and has a comfortalls home; has had no form of venereal diseare, nor sulfered from noctumal emissions; has always been a healthy, active man, and the only point in his history is that about soven years ago he was knocked down by a frightened cow in the street, and was brought home looking, his wife says, "just like a corpse." She avers that he has never been the same man since. Ul las heen married fifteen years and had nine children, of whom five are alive and all healthy. He $h$ s never indulged in spirituous liquors, thongh his farher is a lieavy drinker. His family history is rood.

The patient when I saw him was a good deal emaciated, had an anxious expression, and a dusky, unhealthy complexion. There was no evidence of any pulmonary or cardiac disease. On moving either bip loud crackling sounds were produced, which were proparated down the thigh. Ile complained of pains like being slit with a knife down the legs and in the lower part of the abdomen; sometimes these pains passed up into the epigastric regrion, and then he lost his appetite for a day, but there was never any vomiting or other gastric disturbance of any kind. There was no girdle pain. The patellar teodon-reflex was entirely absent in both limbs; in sitting on the bedside to have this tested bis right foot swung at a normal angle to the leg, while in the left limb the dorsum of the foot and of the leg were in the same straight line, and the great toe curved downwards to the ground; the cutancous veins were noticed to be engorged in both lower extremities, especially so in the left. Tactile sensation was fairly correct in both soles, though it was delayed; but there was well-marked analgesia except in one spot in the waist of the foot. The character of the gait was too much ma-ked by the double hip.joint disease to be trustworthy; but he did not seem to have the $u$ iual feeling of padding in the soles of his feet; he had never noticed any dilficulty about walking in the dark, but soon began to totter when standing with his eyes shut. The glutei muscles were not atrophied, and when standing they were in a condition of spasm, which was probably due to the great laxity of the ligaments. He had now no skin dieease, but last summer while under treatment he said he had an eruption on his chest, which seemed to have been a diffused redness not marked by wheals, vesicles, or papules, and which came and went. When it was fully out it was accompanied by intense itching and burning, but did not seem to have had any relation to, or connexion with. the slitting pains. The gastric, intestinal, and laryngeal functions were normal. For three werks previously his urine had passed away from him while sitting or lying down; the first thing he knew about it was the wetness of his shirt. The vision of his right eye was about normal, but with his left he conld not make out No. 20 Snellen's types at any distance. The pnpils were both a good deal contracted, but retained a feeble amount of accommodation to both light and convergence. They respouded less readily to light than to convergence, so that the Argyll-Robertson phenomenon might be said to have been partially developed. With the ophthalmoscope the fundus of the right eye appeared to be normal ; the fundus of the left was 1 ale, the vessels were small and tortuous, and the optic disc was atrophied.

There could, I think, be no doubt that this was a true case of locomotor ataxia, and of the joint disease which sometimes accompanies it. The salient points seem?d to me to be the particular joints affected; the appearance of the grating prior to any effusion; the great laxity of the ligaments in the ataxic limbs and the early date in the history at which this would seem to have existed; the absence of crises gastriques; the position of the left foot when pendulous, as somewhat complicating the diagnosis; and the differential diagnosis from chronic osteo-arthritis in such a case as this where the locomotor ataxia was not previously known to exist. As regards the question of diagnosis, Dr. Byrom Bramwell ${ }^{1}$ gives three criteria-(1) that this disease is more acute; (2) that ia chronic rheumatic arthritis the smaller joints and the hip are most frequently affected, whercas in locomotor ataxia the knee and shoulder are most often involved; (3) the presence of Jiquid eflusion and dislocations. I have not found any of these criteria of very much help, for my case has lasted very nearly a year, probably quite, and, beyond the fact of another joint having become involved, not much progress secms to have been made. As to the joints affected, besides this one, I bave access to the records of only eight cases. In the case shown by Mr. l'age to the Medical 